\title{
Frequency of TLR4 (1063A/G and 1363C/T) polymorphisms in healthy and HIV-infected Omani individuals and their relationship to viral load and $T$ cell count
}

\author{
E.A. Said ${ }^{1}$, F. Al-Yafei ${ }^{1}$, F. Zadjali ${ }^{2}$, M.S. Al-Balushi' ${ }^{1}$, S.S. Hasson ${ }^{1}$, \\ S.H. Al-Mahroqi' , C.Y. Koh' ${ }^{1}$, K. Al-Naamani ${ }^{4}$, J.Z. Al-Busaidi', \\ M.A. Idris ${ }^{1}$, A. Balkhair ${ }^{3}$ and A.A. Al-Jabri ${ }^{1}$ \\ ${ }^{1}$ Department of Microbiology and Immunology, \\ College of Medicine and Health Sciences, Sultan Qaboos University, Muscat, Oman \\ ${ }^{2}$ Department of Biochemistry, College of Medicine and Health Sciences, \\ Sultan Qaboos University, Muscat, Oman \\ ${ }^{3}$ Department of Medicine, College of Medicine and Health Sciences, \\ Sultan Qaboos University, Muscat, Oman \\ ${ }^{4}$ Department of Medicine, Armed Forces Hospital, Muscat, Oman \\ Corresponding author: E.A. Said \\ E-mail: elias.said@gmail.com \\ Genet. Mol. Res. 15 (2): gmr.15027671 \\ Received September 17, 2015 \\ Accepted December 3, 2015 \\ Published April 4, 2016 \\ DOI http://dx.doi.org/10.4238/gmr.15027671
}

\begin{abstract}
Toll-like receptors (TLRs) are essential elements of the innate immune response to different infections including the infection with human immunodeficiency virus (HIV). Single nucleotide polymorphisms (SNPs) in TLRs such as TLR4 1063A/G and 1363C/T have been found to be associated with changes in CD4 count, viral load (VL), and disease progression during HIV infection. However, the association of these SNPs with the pathogenesis during HIV infection is controversial. We investigated the frequency of TLR4 1063A/G and 1363C/T SNPs in 168 Omani donors [68 HIV-infected patients (>3\% of Omani HIV-infected patients) and 100
\end{abstract}


healthy controls] and the association of these SNPs with the VL, CD8 and CD4 counts, and the immune recovery after cART as observed by CD4 T cell increase. SNPs were analyzed after the amplification of the regions that contain them by polymerase chain reaction (PCR) and sequencing of the PCR products. The TLR4 1063GG genotype was detected in the HIVinfected group only. No association was found between the studied SNPs and the average VL during 1 year of infection, the average CD4 and CD8 count during 1 year of viremia, the nadir CD4 count, the CD4 count when the patient reached $\mathrm{VL}<50$ copies $/ \mathrm{mL}$ due to $\mathrm{CART}$, and the ratio of the CD4 count 3 and 6 months after reaching $V L<50$ copies/mL after CART to the last CD4 count before reaching $\mathrm{VL}<50$ copies $/ \mathrm{mL}$. Our study suggests that TLR4 (1063A/G and 1363C/T) SNPs have no association with the VL or the CD4 and CD8 counts during HIV infection.

Key words: Single nucleotide polymorphism; HIV; CD4 T cell; CD8 T cell

\section{INTRODUCTION}

The main elements of the pathogenesis induced by human immunodeficiency virus (HIV) infection are the depletion of CD4 T cells and the level of the viral load (VL) (Février et al., 2011), but these elements vary between patients (Gaardbo et al., 2012). The presence of single nucleotide polymorphisms (SNPs) is one of the genetic variations that has been shown to be closely related to the variability of these elements (Dean et al., 1996; Liu et al., 1996; Samson et al., 1996; Bleiber et al., 2005). The variation of the VL and the CD4 count among patients infected with HIV has been associated with polymorphisms in different genes, including chemokines and their receptors, human leukocyte antigen, and Toll-like receptors (TLRs) (Poropatich and Sullivan Jr., 2011). TLRs are the main components of the pattern recognition receptors.

The stimulation of TLRs is a fundamental step to induce a wide array of innate immune responses and inflammation, which play an important role in controlling the pathogenesis of infections and their control (Gordon, 2002; Thompson et al., 2011). Many studies have demonstrated the role of some TLRs, such as TLR4, in HIV pathogenesis. TLR4 stimulation by lipopolysaccharide (LPS), found in the blood of HIV-infected patients due to microbial translocation, initiates downstream signaling that induces the production of inflammatory cytokines, such as tumor necrosis factor (TNF)- $\alpha$, interleukin (IL)-1 $\beta$, IL-6 and IL-8 (Báfica et al., 2004; Brenchley et al., 2006; Lester et al., 2008; Chang and Altfeld, 2009; Papadopoulos et al., 2010). The involvement of the TLR4 $1063 \mathrm{~A} / \mathrm{G}$ SNP, which results in the substitution of an aspartic acid with a glycine at amino acid position 299 (Asp299Gly), and the 1363C/T SNP, which results in the substitution of a threonine with an isoleucine at amino acid position 399 (Thr399lle), in the immune pathogenesis leading to acquired immunodeficiency syndrome is controversial (Bochud et al., 2007; Ferwerda et al., 2007; Soriano-Sarabia et al., 2008; Pine et al., 2009; Papadopoulos et al., 2010). Whereas some studies have shown that HIV-infected patients who are carrying a polymorphism in TLR4 (1063A/G and/or $1363 \mathrm{C} / \mathrm{T}$ ) have a high $\mathrm{VL}$, rapid disease progression, low CD4 count, and increased risk of severe infections (Ferwerda et al., 2007; Pine et al., 2009; Papadopoulos et al., 2010), other studies did not find any relation between these SNPs and HIV infection parameters (Bochud et al., 2007; Soriano-Sarabia et al., 2008). These SNPs have been shown to be associated with an increased 
incidence and/or susceptibility to Gram-negative bacterial infections (Ferwerda et al., 2007), respiratory syncytial virus (Awomoyi et al., 2007), or Candida albicans (Van der Graaf et al., 2006) and Plasmodium falciparum infections (Mockenhaupt et al., 2006). Conversely, individuals who harbor these SNPs have been found to be at a decreased risk of certain inflammatory diseases such as atherosclerosis (Kiechl et al., 2002).

Examining the association between these SNPs and the average values of the VL, CD4 and CD8 cell counts, and nadir CD4 when the patients are viremic helps shed light on the relationship between these SNPs and the ability to control the VL and conserve a normal CD4 count before treatment. However, these relationships have not been investigated. Furthermore, the association of these SNPs with the CD4 count after combination antiretroviral therapy (cART) was not previously explored. Thus, in this study, we investigated for the first time the frequency of TLR4 (1063A/G and 1363C/T) SNPs in Omani HIV-infected patients and their association with the average VL and CD4 and CD8 T cell counts over 1 year of viremia. We also examined the relationship between the occurrence of the SNPs and the CD4 cell count at different time points after VL suppression to $<50$ copies/mL with cART.

\section{MATERIAL AND METHODS}

\section{Study population}

Samples from 68 Omani HIV-1-infected (3\% of all Omani HIV-infected patients; Table 1) and 100 Omani healthy individuals were included in this study. The collection of blood samples from patients was performed during the monthly visit at Sultan Qaboos University Hospital (SQUH). Patients participated in the study after giving their consent and their data were collected. Treatment was offered to the patients. The viremic period was due to noncompliance of the patients or because their CD4 count was higher than 200 cells $/ \mathrm{mm}^{3}$, a cell count at which it was not mandatory to put patients on treatment. The Medical Research Ethics Committee of the Sultan Qaboos University approved the study. Patients and donors enrolled in this study signed informed consent forms prior to their participation.

Table 1. Characteristics of HIV-infected patients at their entry into the cohort.
\begin{tabular}{l|c}
\hline Parameter & Value \\
\hline $\mathrm{N}$ & 68 \\
\hline Age (years) & $38 \pm 11$ \\
\hline Gender $\%$ women) & $28(41.1)$ \\
\hline CD4 count (cells/mm $\mathrm{mm}^{3}$ & $58526.81 \pm 749.8$ \\
\hline HIV viral load (copies/mL) & \\
\hline Average values \pm standard deviation are shown for each parameter. CD4 T cell count was investigated by flow \\
cytometry and the HIV viral load was measured by real-time RT-PCR.
\end{tabular}

\section{Measurement of CD4 T cell count and VL}

A 5-mL blood sample was collected from each patient into a blood collection tube treated with EDTA. CD4 T cell count was obtained using flow cytometery (Cytomics FC 500, Beckman Coulter, Inc., Switzerland). Cells were labeled using tetra-chrome ${ }^{\text {TM }}$ CD45-FITC/CD4-RDI/CD8ECD and CD3-PC5. The levels of HIV-1 RNA in the plasma were measured using COBAS Kit (AmpliPrep/COBAS TaqMan HIV-1 Test v2.0; Roche Molecular Diagnostics, USA) according to the manufacturer instructions. 


\section{DNA extraction and amplification}

QIAamp DNA Mini Kit (QIAGEN, USA) was used to extract genomic DNA from blood according to the manufacturer protocol and samples were kept at $-80^{\circ} \mathrm{C}$. A spectrophotometer was used to determine DNA concentration (NanoDrop Technology, USA). Polymerase chain reaction (PCR) assays were performed using AmpliTaq Gold ${ }^{\circledR}$ PCR master mix (Applied Biosystems, USA): an initial denaturation at $95^{\circ} \mathrm{C}$ for $5 \mathrm{~min}$ and 30 cycles of an annealing step $\left(95^{\circ} \mathrm{C}\right.$ for $\left.15 \mathrm{~s}\right)$, a polymerization step $\left(57^{\circ} \mathrm{C}\right.$ for $\left.15 \mathrm{~s}\right)$ and an elongation step $\left(72^{\circ} \mathrm{C}\right.$ for $\left.1 \mathrm{~min}\right)$. Before termination, another cycle $\left(72^{\circ} \mathrm{C}\right.$ for $7 \mathrm{~min}$ ) was performed. The primer sequences for TLR4 (rs4986790; 1036A/G) were: forward 5'-GATTAGCATACTTAGACTACTACCTCGATG-3' and reverse 5'GATCAACTTCTGAAAAAGCATTCCCAC-3'. The primers sequences for TLR4 (rs4986791; 1363C/T) were: forward 5'-GGTTGCTGTTCTCAAAGTGATTTTGGGACAA-3' and reverse 5'ACTGAGAGAGGTCCAGGAAGGTCA-3'.

\section{DNA sequencing}

DNA sequencing was performed using PCR products treated as previously described by our group (Said et al., 2014). In brief, shrimp alkaline phosphatase/exonuclease I was used to remove the excess dNTPs and primers. Then, purified DNA was prepared for sequencing using Big Dye $^{\circledR}$ (ThermoFisher, USA) and reverse primer. PCR conditions were carried out again (as described above) and the cycles were repeated 34 times. Precipitation of DNA was done using absolute ethanol and sodium acetate at room temperature for $15 \mathrm{~min}$. Ethanol was then removed, formamide was added, and the mixture was heated at $95^{\circ} \mathrm{C}$ for $5 \mathrm{~min}$. The plate was then set on an automatic sequencer (Applied Biosystems 3130xl Genetic Analyzer). Sequence analysis was performed using the Sequencing Analysis Software v5.2 (Applied Biosystems) and the Lasergene software (DNASTAR, USA) was used for sequence alignment.

\section{Statistical analysis}

The Z-test was used to evaluate the differences between frequencies of genotypes when comparing healthy and HIV-infected individuals. The presence of significance in the genotype associations with HIV VL, the CD8 and CD4 counts, and the different measurements of CD4 T cells (different ratios and periods) were assessed using linear regression for the $P$ value adjusted for age and gender and the unpaired nonparametric $t$-test was used for non-adjusted $P$ value. The presence of significant differences between frequencies of the genotypes between patients grouped based on the CD4 count after reaching VL $<50$ copies/mL due to CART was evaluated using logistic regression for the $\mathrm{P}$ value adjusted for age and gender and the chi-square test for the non-adjusted $P$ value. The additive model (dominant and recessive) and the neutral model (Lettre et al., 2007) were used. The SPSS 15.0 software (Chicago, USA) was used for data analysis.

\section{RESULTS}

\section{Frequency of the TLR4 1063A/G and 1363C/T SNPs in HIV-infected patients and controls}

Among HIV-infected patients, 83.8\% had the TLR4 1063 AA genotype, 10.3\% were heterozygous (AG) and 5.9\% were homozygous for the SNP allele (GG) (Figure 1A and Table 2). In the control 
group, $89 \%$ had the AA genotype, $11 \%$ were heterozygous (AG) and 0 individuals were homozygous for the SNP allele (GG) (Figure 1B and Table 2). Thus, the TLR4 1063 (GG) genotype was found in HIV-infected patients only $(P=0.014)$; however, the $P$ value was not significant when the Bonferroni correction was applied. Moreover, $86.8 \%$ of the HIV-infected patients carried the TLR4 1363 CC genotype, $11.8 \%$ were heterozygous (CT) and $1.4 \%$ were homozygous for the SNP allele (TT) (Figure $1 \mathrm{C}$ and Table 2). In the control group, $91 \%$ carried the CC genotype, $9 \%$ were heterozygous (CT) and none were homozygous for the SNP allele (TT) (Figure 1D and Table 2). All tested SNPs except one (TLR4 1063A/G in HIV-infected patients; $P=0.0008$ ) were in Hardy-Weinberg equilibrium (HWE; Table 2). We used the same primers for the TLR4 1063 (A/G) SNP to genotype the control group. Hence, the lack of equilibrium was not a result of a problem in the technique, but might be due to a random effect and/or the sample size. Similar results have been described previously (Pine et al., 2009).
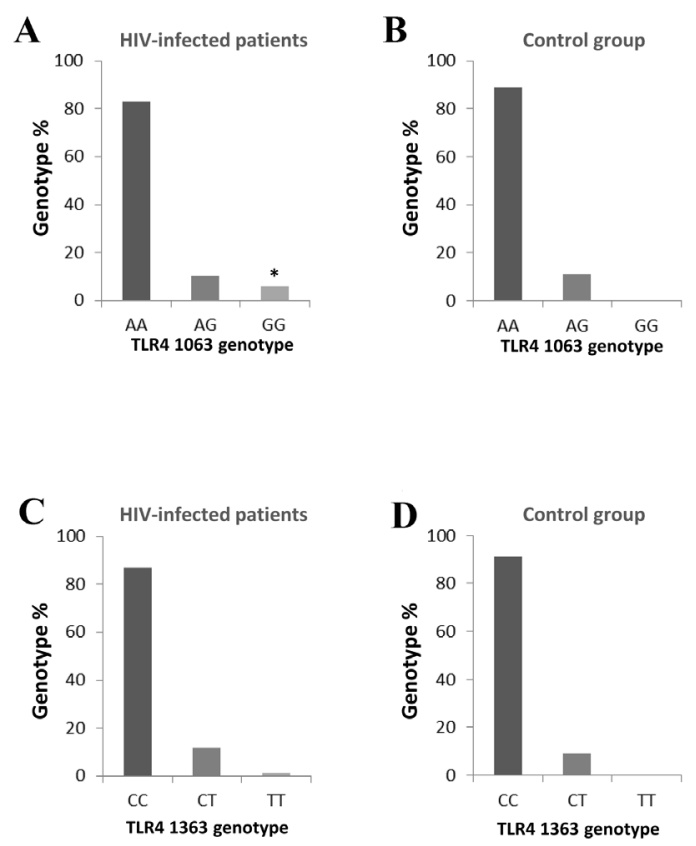

Figure 1. Frequencies of the different genotypes of TLR4 SNPs (1063A/G and 1363C/T). A. TLR4 position 1063 genotypes in HIV-infected patients. B. TLR4 position 1063 genotypes in the control group. C. TLR4 position 1363 genotypes in HIV-infected male patients. D. TLR4 position 1363 genotypes in the control group. The regions containing the TLR4 SNPs from different donors were amplified by PCR and sequenced. The frequency of each genotype was calculated. ${ }^{*} \mathrm{P}$ value $<0.05$.

Table 2. SNPs and allele frequency in TLR4 for both control and HIV-infected populations.

\begin{tabular}{|c|c|c|c|c|c|c|c|c|c|c|c|}
\hline \multirow[t]{2}{*}{ Gene } & \multicolumn{5}{|c|}{ HIV-infected population [N (\%)] } & \multicolumn{5}{|c|}{ Control population [N (\%)] } & \multirow[t]{2}{*}{ F. Diff. } \\
\hline & \multicolumn{3}{|c|}{ Genotype } & $\mathrm{F}$ & HWE & \multicolumn{3}{|c|}{ Genotype } & $\mathrm{F}$ & HWE & \\
\hline \multirow[t]{2}{*}{ TLR4 $1063 \mathrm{~A} / \mathrm{G}$} & AA & $A G$ & GG & \multirow[t]{2}{*}{0.89} & \multirow[t]{2}{*}{0.0008} & AA & $A G$ & GG & \multirow[t]{2}{*}{0.94} & \multirow[t]{2}{*}{0.56} & \multirow[t]{2}{*}{0.06} \\
\hline & $57(83.8)$ & $7(10.3)$ & $4(5.9)$ & & & $89(89)$ & $11(11)$ & $0(0)$ & & & \\
\hline \multirow[t]{2}{*}{ TLR4 $1363 \mathrm{C} / \mathrm{T}$} & CC & CT & TT & \multirow[t]{2}{*}{0.93} & \multirow[t]{2}{*}{0.26} & $\mathrm{CC}$ & CT & TT & \multirow[t]{2}{*}{0.95} & \multirow[t]{2}{*}{0.64} & \multirow[t]{2}{*}{0.27} \\
\hline & $59(86.8)$ & $8(11.8)$ & $1(1.4)$ & & & $91(91)$ & $9(9)$ & $0(0)$ & & & \\
\hline
\end{tabular}

$\mathrm{F}=$ allele frequency; $\mathrm{F}$. Diff. $=$ frequency difference. Parameters were calculated using Online Encyclopedia for Genetic Epidemiology studies (OEGE) and DeFinetti program - Online Hardy Weinberg equilibrium (HWE) and Association Testing - Institute für Humangenetik. 


\section{Relationship between TLR4 SNPs (1063A/G and 1363C/T) and the CD4 and CD8 cell counts and VL}

To examine whether TLR4 SNPs (1063A/G and 1363C/T) are associated with the evolution of HIV-1 pathogenesis, we investigated the association of the TLR4 alleles with the average VL and CD8 and CD4 counts during 1 year of viremia. The use of the average count to investigate such associations allows a better assessment of the long-term effect of these SNPs as opposed to the use of cross-sectional values (Said et al., 2014). Moreover, we investigated the association of these SNPs with the nadir CD4 count and the CD4 count when the patient reached $\mathrm{VL}<50$ copies $/ \mathrm{mL}$ because of cART. We also examined the relationship between these SNPs and the improvement of the CD4 count, which reflects the recovery of the immune system. This was done by assessing the ratio of the CD4 count 3 and 6 months after reaching $\mathrm{VL}<50$ copies $/ \mathrm{mL}$ because of CART to the last CD4 count before reaching $\mathrm{VL}<50 \mathrm{copies} / \mathrm{mL}$ and to the nadir CD4. No association was observed between TLR4 genotypes and the average CD4 count and the average VL during the viremic period ( $P>0.1$; Tables 3,4 , and 5$)$. Also, the CD8 count did not show any association with TLR4 genotypes (Tables 3, 4, and 5), although a trend of an association with the TLR4 1363 (TT) genotype ( $P=0.092$ not adjusted; Table 3) was observed in the dominant model (CC + CT, TT). Furthermore, we did not find any association between these SNPs and the nadir CD4, the CD4 count when the patient reached $\mathrm{VL}<50$ copies/mL because of CART, and the ratio of the CD4 count 3 and 6 months after reaching $\mathrm{VL}<$ 50 copies $/ \mathrm{mL}$ because of cART to the last CD4 count before reaching $\mathrm{VL}<50$ copies/mL (Tables 3,4 and 5).

\begin{tabular}{|c|c|c|c|c|}
\hline & \multicolumn{2}{|c|}{ TLR4 1063} & \multicolumn{2}{|c|}{ TLR4 1363} \\
\hline Genotype & $A A+A G$ & GG & $\mathrm{CC}+\mathrm{CT}$ & TT \\
\hline CD4 (cells $/ \mathrm{mm}^{3}$ ) & $271.4(20.2)$ & $233.75(53.8)$ & $268.1(19.4)$ & $330(18.5)$ \\
\hline$P$ value & \multicolumn{2}{|c|}{0.64} & \multicolumn{2}{|c|}{0.67} \\
\hline$P$ adj. & \multicolumn{2}{|c|}{0.75} & \multicolumn{2}{|c|}{0.87} \\
\hline CD8 (cells $/ \mathrm{mm}^{3}$ ) & $877.2(2)$ & $890.2(1.6)$ & $794.3(398)$ & $1012.1(24.1)$ \\
\hline$P$ value & \multirow{2}{*}{\multicolumn{2}{|c|}{$\begin{array}{l}0.19 \\
0.88\end{array}$}} & \multirow{2}{*}{\multicolumn{2}{|c|}{0.09}} \\
\hline$P$ adj. & & & & \\
\hline VL (copies $/ \mathrm{mL}$ ) & $4.2^{*}(0.1)$ & $4.3^{*}(0.6)$ & $4.2^{*}(0.1)$ & $4.4^{*}(0.1)$ \\
\hline$P$ value & \multicolumn{2}{|c|}{0.83} & \multicolumn{2}{|c|}{0.84} \\
\hline $\mathrm{P}$ adj. & \multicolumn{2}{|c|}{0.15} & \multicolumn{2}{|c|}{0.91} \\
\hline CD4 nadir (cells $/ \mathrm{mm}^{3}$ ) & $40.7(1.2)$ & $13.5(2.5)$ & $57.4(8.379)$ & $43(1.8)$ \\
\hline$P$ value & \multirow{2}{*}{\multicolumn{2}{|c|}{$\begin{array}{l}0.16 \\
0.48\end{array}$}} & \multirow{2}{*}{\multicolumn{2}{|c|}{$\begin{array}{l}0.94 \\
0.08\end{array}$}} \\
\hline$P$ adj. & & & & \\
\hline CD4/VL $<50\left(\right.$ cells $\left./ \mathrm{mm}^{3}\right)$ & $318.3(28.9)$ & $425.50(158.8)$ & $325.25(29.5)$ & $388(20.4)$ \\
\hline$P$ value & \multicolumn{2}{|c|}{0.33} & \multirow{2}{*}{\multicolumn{2}{|c|}{$\begin{array}{l}0.78 \\
0.69\end{array}$}} \\
\hline$P$ adj. & \multicolumn{2}{|c|}{0.38} & & \\
\hline CD4 (3M) (cells/mm³) & $345.6(315.5)$ & $513(134.7)$ & $353.8(31.4)$ & $610(24.1)$ \\
\hline$P$ value & \multirow{2}{*}{\multicolumn{2}{|c|}{$\begin{array}{l}0.15 \\
0.17\end{array}$}} & & \\
\hline$P$ adj. & & & \multicolumn{2}{|c|}{$\begin{array}{l}0.26 \\
0.27\end{array}$} \\
\hline CD4 (6M) (cells $/ \mathrm{mm}^{3}$ ) & $398(33)$ & $506.5(108.1)$ & $400.9(31.7)$ & $692(26.2)$ \\
\hline$P$ value & \multirow{2}{*}{\multicolumn{2}{|c|}{$\begin{array}{l}0.36 \\
0.33\end{array}$}} & \multirow{2}{*}{\multicolumn{2}{|c|}{$\begin{array}{c}0.2 \\
0.36\end{array}$}} \\
\hline$P$ adj. & & & & \\
\hline
\end{tabular}

$\mathrm{VL}=$ viral load; $3 \mathrm{M}=3$ months; $6 \mathrm{M}=6$ months; ${ }^{*} \log 10$ mean. Data are reported as means \pm standard error of the mean. $P$ value and $P$ value adjusted ( $P$ adj.) for age and gender are shown. 


\begin{tabular}{|c|c|c|c|c|}
\hline \multirow[b]{2}{*}{ Genotype } & \multicolumn{2}{|c|}{ TLR4 1063} & \multicolumn{2}{|c|}{ TLR4 1363} \\
\hline & AA & $G G+G A$ & $\mathrm{CC}$ & $\mathrm{TT}+\mathrm{TC}$ \\
\hline CD4 (cells $\left./ \mathrm{mm}^{3}\right)$ & $275.2(22.4)$ & $249.1(28.1)$ & $271.4(21.9)$ & $255(29.1)$ \\
\hline$P$ value & \multicolumn{2}{|c|}{0.5} & \multicolumn{2}{|c|}{0.77} \\
\hline $\mathrm{P}$ adj. & \multicolumn{2}{|c|}{0.58} & \multicolumn{2}{|c|}{0.83} \\
\hline CD8 (cells $/ \mathrm{mm}^{3}$ ) & $974.8(11)$ & $1015.5(12)$ & $960.9(27)$ & $1016^{*}(10)$ \\
\hline $\mathrm{P}$ value & \multicolumn{2}{|c|}{0.81} & \multicolumn{2}{|c|}{0.41} \\
\hline$P$ adj. & \multicolumn{2}{|c|}{0.78} & \multicolumn{2}{|c|}{0.4} \\
\hline $\mathrm{VL}$ (copies/mL) & $4.1^{*}(0.1)$ & $4.5^{*}(0.2)$ & $4.2^{*}(0.1)$ & $4.5^{*}(0.3)$ \\
\hline$P$ value & \multicolumn{2}{|c|}{0.25} & \multicolumn{2}{|c|}{0.39} \\
\hline$P$ adj. & \multicolumn{2}{|c|}{0.25} & \multicolumn{2}{|c|}{0.45} \\
\hline CD4 nadir (cells/mm $/ \mathrm{mm}^{3}$ ) & $40.7(1.23)$ & $27.4(1.5)$ & $38.9(1.2)$ & $33.1(1)$ \\
\hline$P$ value & \multicolumn{2}{|c|}{0.44} & \multicolumn{2}{|c|}{0.77} \\
\hline$P$ adj. & \multicolumn{2}{|c|}{0.41} & \multicolumn{2}{|c|}{0.76} \\
\hline CD4/VL $<50\left(\right.$ cells $\left./ \mathrm{mm}^{3}\right)$ & $323.2(31.7)$ & $341.8(75.3)$ & $330.6(32.9)$ & $298.7(35.2)$ \\
\hline$P$ value & \multicolumn{2}{|c|}{0.81} & \multicolumn{2}{|c|}{0.71} \\
\hline$P$ adj. & \multicolumn{2}{|c|}{0.76} & \multicolumn{2}{|c|}{0.84} \\
\hline CD4 (3M) (cells/mm³) & $354.4(32.6)$ & $379.4(94.3)$ & $359.4(33.7)$ & $354.9(88.2)$ \\
\hline $\mathrm{P}$ value & \multicolumn{2}{|c|}{0.76} & \multicolumn{2}{|c|}{0.96} \\
\hline$P$ adj. & \multicolumn{2}{|c|}{0.72} & \multicolumn{2}{|c|}{0.97} \\
\hline CD4 (6M) (cells $\left./ \mathrm{mm}^{3}\right)$ & $405.6(35.9)$ & $411.8(67.5)$ & $406.1(35.4)$ & $410.7(64.5)$ \\
\hline$P$ value & \multicolumn{2}{|c|}{0.94} & \multicolumn{2}{|c|}{0.96} \\
\hline$P$ adj. & \multicolumn{2}{|c|}{0.77} & \multicolumn{2}{|c|}{0.82} \\
\hline
\end{tabular}

\begin{tabular}{|c|c|c|c|c|c|c|}
\hline \multirow{2}{*}{ Genotype } & \multicolumn{3}{|c|}{ TLR4 1063} & \multicolumn{3}{|c|}{ TLR4 1363} \\
\hline & AA & GG & AG & $\mathrm{CC}$ & TT & $\mathrm{CT}$ \\
\hline CD4 (cells/mm³) & $275.2(22.4)$ & $233.75(53.8)$ & $243.7(20.5)$ & $271.4(21.9)$ & $330(18.5)$ & $245.6(24.6)$ \\
\hline$P$ value & \multicolumn{3}{|c|}{0.79} & \multicolumn{3}{|c|}{0.84} \\
\hline$P$ adj. & \multicolumn{3}{|c|}{0.62} & \multicolumn{3}{|c|}{0.8} \\
\hline CD8 (cells $\left./ \mathrm{mm}^{3}\right)$ & $974.8(11)$ & $890.2(1.6)$ & $981.1(18)$ & $960.9(27)$ & $1012.1(24.1)$ & $1020.2(12.4)$ \\
\hline $\mathrm{P}$ value & \multicolumn{3}{|c|}{0.97} & \multicolumn{3}{|c|}{0.23} \\
\hline $\mathrm{P}$ adj. & \multicolumn{3}{|c|}{0.78} & \multicolumn{3}{|c|}{0.55} \\
\hline $\mathrm{VL}$ (copies $/ \mathrm{mL}$ ) & $4.1^{*}(0.1)$ & $4.3^{*}(0.6)$ & $4.6^{*}(0.2)$ & $4.2^{*}(0.1)$ & $4.4^{*}(0.1)$ & $4.5^{*}(0.2)$ \\
\hline $\mathrm{P}$ value & \multicolumn{3}{|c|}{0.46} & \multicolumn{3}{|c|}{0.69} \\
\hline $\mathrm{P}$ adj. & \multicolumn{3}{|c|}{0.23} & \multicolumn{3}{|c|}{0.44} \\
\hline CD4 nadir (cells $/ \mathrm{mm}^{3}$ ) & $40.7(1.23)$ & $13.5(2.5)$ & $41.3(3.1)$ & $38.9(1.2)$ & $43(1.8)$ & $32(1.9)$ \\
\hline $\mathrm{P}$ value & \multicolumn{3}{|c|}{0.37} & \multicolumn{3}{|c|}{0.94} \\
\hline $\mathrm{P}$ adj. & \multicolumn{3}{|c|}{0.67} & \multicolumn{3}{|c|}{0.72} \\
\hline CD4/VL $<50\left(\right.$ cells $\left./ \mathrm{mm}^{3}\right)$ & $323.2(31.7)$ & $425.50(158.8)$ & $274.8(24.4)$ & $330.6(32.9)$ & $388(20.4)$ & $284.3(28.7)$ \\
\hline$P$ value & \multicolumn{3}{|c|}{0.56} & \multicolumn{3}{|c|}{0.85} \\
\hline $\mathrm{P}$ adj. & \multicolumn{3}{|c|}{0.99} & \multicolumn{3}{|c|}{0.77} \\
\hline CD4 (3M) (cells $\left./ \mathrm{mm}^{3}\right)$ & $354.4(32.6)$ & $513(134.7)$ & $272.6(36.6)$ & $359.4(33.7)$ & $610(24.1)$ & $312.3(28.4)$ \\
\hline $\mathrm{P}$ value & \multicolumn{3}{|c|}{0.27} & \multicolumn{3}{|c|}{0.47} \\
\hline $\mathrm{P}$ adj. & \multicolumn{3}{|c|}{0.88} & \multicolumn{3}{|c|}{0.85} \\
\hline CD4 (6M) (cells $\left./ \mathrm{mm}^{3}\right)$ & $405.6(35.9)$ & $506.5(108.1)$ & $336(28.6)$ & $406.1(35.4)$ & $692(26.2)$ & $363.8(22.4)$ \\
\hline $\mathrm{P}$ value & \multicolumn{3}{|c|}{0.53} & \multicolumn{3}{|c|}{0.4} \\
\hline $\mathrm{P}$ adj. & \multicolumn{3}{|c|}{0.95} & \multicolumn{3}{|c|}{0.97} \\
\hline
\end{tabular}

\section{DISCUSSION}

Our results showed that the frequency of individuals with the TLR4 1063GG genotype was significantly higher in the HIV-infected patients than the control group $(P=0.014)$. However, 
the SNPs in TLR4 (1063A/G and 1363C/T) were not associated with average VL, CD8 and CD4 counts, or the improvement of CD4 count after CART in our cohort. The frequencies of the TLR4 SNPs in Omani HIV-infected and control individuals enrolled in this study were similar to those found in Spanish HIV-infected and control individuals (Soriano-Sarabia et al., 2008). Moreover, the frequencies in the healthy population were similar to those in patients with tonsillar disease and infected with Streptococcus pyogenes (Liadaki et al., 2011). The significant difference in the frequency of TLR4 1063GG genotype between the HIV-infected patients and the control group might be due to differences in the ethnic background of the enrolled individuals in both groups although they are all Omanis. This cannot be related to susceptibility to HIV infection based on our results as the control group was not exposed to the virus.

Conflicting results have been reported about the association of TLR4 (1063A/G and 1363C/T) SNPs with parameters of HIV pathogenesis (Bochud et al., 2007; Ferwerda et al., 2007; Soriano-Sarabia et al., 2008; Pine et al., 2009; Papadopoulos et al., 2010). Indeed, although TLR4 (1063A/G and 1363C/T) SNPs were found to be associated with a high peak VL in Swiss HIVinfected patients (Pine et al., 2009), no association was found between the VL at the entry to the cohort and these SNPs in a Spanish cohort (Soriano-Sarabia et al., 2008). Our results are in agreement with those found in Spanish HIV-infected patients, as we did not find any association between these SNPs and the average VL during 1 year of infection. Furthermore, studies in HIVinfected African patients in Tanzania and Caucasian patients in Greece showed the presence of associations between TLR4 (1063A/G and 1363C/T) SNPs and a decrease in CD4 count and increased frequency of serious infection in HIV-infected individuals with a nadir CD4 count $<100$ cell $/ \mathrm{mm}^{3}$, respectively (Ferwerda et al., 2007; Papadopoulos et al., 2010). In contrast, studies in Swiss and Spanish HIV-infected patients showed the absence of associations between these SNPs and the CD4 count as measured by the slope of CD4 count decline and the CD4 count at entry to the cohort, respectively (Bochud et al., 2007; Soriano-Sarabia et al., 2008; Pine et al., 2009). Our results in Omani HIV-infected patients corroborate with the results in the Swiss and Spanish cohorts, as we did not find significant associations between these SNPs and the CD4 count during 1 year of viremia, the nadir CD4 count, the CD4 count when the patient reached $V L<$ 50 copies $/ \mathrm{mL}$ because of CART, and the ratio of the CD4 count 3 and 6 months after reaching VL $<50$ copies $/ \mathrm{mL}$ because of CART to the last CD4 count before reaching $\mathrm{VL}<50$ copies $/ \mathrm{mL}$ and to the nadir CD4. It is important to highlight that associations between a high average CD4 count and SNPs in TLR7 and TLR9 were found in this Omani cohort (Said et al., 2014), which underline the weakness of the influence of the TLR4 SNPs on CD4 T cells during HIV infection. Of note, the average CD8 count during 1 year of viremia was also not associated with these SNPs, as shown for the first time by our results. Different findings can explain the potential influence of TLR4 on CD8 and CD4 count and HIV VL. TLR4 detects LPS from Gram-negative bacteria and this stimulates the apoptosis of memory CD4 T cells and the activation of CD8 T cells (Funderburg et al., 2008). Hence, this can occur during HIV infection due to microbial translocation from the gut to the blood (Brenchley et al., 2006). The microbial translocation may also lead to the activation of monocytes causing the production of IL-10 by these cells, thus affecting the proliferation and function of the CD4 T cells (Said et al., 2010). In addition, TLR4 levels in peripheral blood mononuclear cells were found to be correlated with HIV RNA load (Lester et al., 2009). Therefore, the discordance in the results about the influence of TLR4 SNPs on the VL and CD4 count during HIV infection might be due to the differences in blood LPS levels between the different cohorts. In addition, the presence of other determinants such as TLR9, which can detect a broader spectrum of bacteria as compared 
to TLR4 because of its ability to recognize CpG DNA, might influence the CD4 count and VL as shown by our group and others (Soriano-Sarabia et al., 2008; Pine et al., 2009; Said et al., 2014). The difference in the ethnicities among the different groups might also provide an explanation for this disagreement but this was not examined in our study.

This is the first study that describes the frequency of TLR4 (1063A/G and 1363C/T) polymorphisms in the Omani population. Our results do not support the presence of an association between TLR4 (1063A/G and 1363C/T) SNPs on the VL, the CD8 and CD4 counts, or the increase in CD4 after controlling viremia with CART during HIV infection. Further investigations on a larger sample size would be necessary to confirm these findings.

\section{Conflicts of interest}

The authors declare no conflict of interest.

\section{ACKNOWLEDGMENTS}

Research supported by the Research Council of the Sultanate of Oman (\#RC/MED/ MICR/11/01) and the College of Medicine and Health Sciences, Sultan Qaboos University, Oman. We would like to thank Mr. Mohamad Al-Kindi, Mr. Abdul Rahim Al-Abri, Ms. Hameeda Al-Barwani, and Ms. Sana Hasari from the Biochemistry Department, and Mr. C.M. Varghese, Mr. Mani Suriyan, and Ms. Faiza Al-yahyai from the Genetic Department, College of Medicine and Health Sciences, Sultan Qaboos University, for their technical help.

\section{REFERENCES}

Awomoyi AA, Rallabhandi P, Pollin TI, Lorenz E, et al. (2007). Association of TLR4 polymorphisms with symptomatic respiratory syncytial virus infection in high-risk infants and young children. J. Immunol. 179: 3171-3177. http://dx.doi.org/10.4049/ ïmunol.179.5.3171

Báfica A, Scanga CA, Schito M, Chaussabel D, et al. (2004). Influence of coinfecting pathogens on HIV expression: evidence for a role of Toll-like receptors. J. Immunol. 172: 7229-7234. http://dx.doi.org/10.4049/jimmunol.172.12.7229

Bleiber G, May M, Martinez R, Meylan P, et al.; Swiss HIV Cohort Study (2005). Use of a combined ex vivolin vivo population approach for screening of human genes involved in the human immunodeficiency virus type 1 life cycle for variants influencing disease progression. J. Virol. 79: 12674-12680. http://dx.doi.org/10.1128/JVI.79.20.12674-12680.2005

Bochud PY, Hersberger M, Taffé P, Bochud M, et al.; Swiss HIV Cohort Study (2007). Polymorphisms in Toll-like receptor 9 influence the clinical course of HIV-1 infection. AIDS 21: 441-446. http://dx.doi.org/10.1097/QAD.0b013e328012b8ac

Brenchley JM, Price DA, Schacker TW, Asher TE, et al. (2006). Microbial translocation is a cause of systemic immune activation in chronic HIV infection. Nat. Med. 12: 1365-1371. http://dx.doi.org/10.1038/nm1511

Chang JJ and Altfeld M (2009). TLR-mediated immune activation in HIV. Blood 113: 269-270. http://dx.doi.org/10.1182/ blood-2008-10-184598

Dean M, Carrington M, Winkler C, Huttley GA, et al. (1996). Genetic restriction of HIV-1 infection and progression to AIDS by a deletion allele of the CKR5 structural gene. Hemophilia Growth and Development Study, Multicenter AIDS Cohort Study, Multicenter Hemophilia Cohort Study, San Francisco City Cohort, ALIVE Study. Science 273: 1856-1862. http://dx.doi. org/10.1126/science.273.5283.1856

Ferwerda B, Kibiki GS, Netea MG, Dolmans WM, et al. (2007). The toll-like receptor 4 Asp299Gly variant and tuberculosis susceptibility in HIV-infected patients in Tanzania. AIDS21: 1375-1377. http://dx.doi.org/10.1097/QAD.0b013e32814e6b2d

Février M, Dorgham K and Rebollo A (2011). CD4+ T cell depletion in human immunodeficiency virus (HIV) infection: role of apoptosis. Viruses 3: 586-612. http://dx.doi.org/10.3390/v3050586

Funderburg N, Luciano AA, Jiang W, Rodriguez B, et al. (2008). Toll-like receptor ligands induce human T cell activation and death, a model for HIV pathogenesis. PLoS One 3: e1915.

Gaardbo JC, Hartling HJ, Gerstoft J and Nielsen SD (2012). Incomplete immune recovery in HIV infection: mechanisms, relevance 
for clinical care, and possible solutions. Clin. Dev. Immunol. 2012: 670957. http://dx.doi.org/10.1155/2012/670957

Gordon S (2002). Pattern recognition receptors: doubling up for the innate immune response. Cell 111: 927-930. http://dx.doi. org/10.1016/S0092-8674(02)01201-1

Kiechl S, Lorenz E, Reindl M, Wiedermann CJ, et al. (2002). Toll-like receptor 4 polymorphisms and atherogenesis. N. Engl. J. Med. 347: 185-192. http://dx.doi.org/10.1056/NEJMoa012673

Lester RT, Yao XD, Ball TB, McKinnon LR, et al. (2008). Toll-like receptor expression and responsiveness are increased in viraemic HIV-1 infection. AIDS 22: 685-694. http://dx.doi.org/10.1097/QAD.0b013e3282f4de35

Lester RT, Yao XD, Ball TB, McKinnon LR, et al. (2009). HIV-1 RNA dysregulates the natural TLR response to subclinical endotoxemia in Kenyan female sex-workers. PLoS One 4: e5644. http://dx.doi.org/10.1371/journal.pone.0005644

Lettre G, Lange C and Hirschhorn JN (2007). Genetic model testing and statistical power in population-based association studies of quantitative traits. Genet. Epidemiol. 31: 358-362. http://dx.doi.org/10.1002/gepi.20217

Liadaki K, Petinaki E, Skoulakis C, Tsirevelou P, et al. (2011). Toll-like receptor 4 gene (TLR4), but not TLR2, polymorphisms modify the risk of tonsillar disease due to Streptococcus pyogenes and Haemophilus influenzae. Clin. Vaccine Immunol. 18: 217-222. http://dx.doi.org/10.1128/CVI.00460-10

Liu R, Paxton WA, Choe S, Ceradini D, et al. (1996). Homozygous defect in HIV-1 coreceptor accounts for resistance of some multiply-exposed individuals to HIV-1 infection. Cell 86: 367-377. http://dx.doi.org/10.1016/S0092-8674(00)80110-5

Mockenhaupt FP, Cramer JP, Hamann L, Stegemann MS, et al. (2006). Toll-like receptor (TLR) polymorphisms in African children: Common TLR-4 variants predispose to severe malaria. Proc. Natl. Acad. Sci. USA 103: 177-182. http://dx.doi. org/10.1073/pnas.0506803102

Papadopoulos Al, Ferwerda B, Antoniadou A, Sakka V, et al. (2010). Association of toll-like receptor 4 Asp299Gly and Thr399lle polymorphisms with increased infection risk in patients with advanced HIV-1 infection. Clin. Infect. Dis. 51: 242-247. http:// dx.doi.org/10.1086/653607

Pine SO, McElrath MJ and Bochud PY (2009). Polymorphisms in toll-like receptor 4 and toll-like receptor 9 influence viral load in a seroincident cohort of HIV-1-infected individuals. AIDS 23: 2387-2395. http://dx.doi.org/10.1097/QAD.0b013e328330b489

Poropatich K and Sullivan DJ, Jr. (2011). Human immunodeficiency virus type 1 long-term non-progressors: the viral, genetic and immunological basis for disease non-progression. J. Gen. Virol. 92: 247-268. http://dx.doi.org/10.1099/vir.0.027102-0

Said EA, Dupuy FP, Trautmann L, Zhang Y, et al. (2010). Programmed death-1-induced interleukin-10 production by monocytes impairs CD4+ T cell activation during HIV infection. Nat. Med. 16: 452-459. http://dx.doi.org/10.1038/nm.2106

Said EA, Al-Yafei F, Zadjali F, Hasson SS, et al. (2014). Association of single-nucleotide polymorphisms in TLR7 (GIn11Leu) and TLR9 (1635A/G) with a higher CD4T cell count during HIV infection. Immunol. Lett. 160: 58-64. http://dx.doi. org/10.1016/j.imlet.2014.04.005

Samson M, Libert F, Doranz BJ, Rucker J, et al. (1996). Resistance to HIV-1 infection in caucasian individuals bearing mutant alleles of the CCR-5 chemokine receptor gene. Nature 382: 722-725. http://dx.doi.org/10.1038/382722a0

Soriano-Sarabia N, Vallejo A, Ramírez-Lorca R, Rodríguez MdelM, et al. (2008). Influence of the Toll-like receptor 9 1635A/G polymorphism on the CD4 count, HIV viral load, and clinical progression. J. Acquir. Immune Defic. Syndr. 49: 128-135. http://dx.doi.org/10.1097/QAl.0b013e318184fb41

Thompson MR, Kaminski JJ, Kurt-Jones EA and Fitzgerald KA (2011). Pattern recognition receptors and the innate immune response to viral infection. Viruses 3: 920-940. http://dx.doi.org/10.3390/v3060920

Van der Graaf CA, Netea MG, Morré SA, Den Heijer M, et al. (2006). Toll-like receptor 4 Asp299Gly/Thr399lle polymorphisms are a risk factor for Candida bloodstream infection. Eur. Cytokine Netw. 17: 29-34. 